\title{
To compare the efficacy of triple therapy with furazolidone, amoxicillin and omeprazole for two weeks and three weeks in the eradication of Helicobacter pylori in Bangladeshi duodenal ulcer patients
}

\author{
Saha $\mathrm{SK}^{1}$, Saha $\mathrm{SK}^{2}$, Masud $\mathrm{H}^{2}$, Islam N ${ }^{3}$, Raihan $\mathrm{ASMA}^{2}$, Roy $\mathrm{PK}^{2}$, Hasan $\mathrm{M}^{2}$, \\ ${ }^{1}$ Department of Gastroenterology, Sir Salimullah Medical College \& Mitford Hospital, Dhaka. \\ ${ }^{2}$ Department of Gastroenterology, Bangabandhu Sheikh Mujib Medical University, Shahbag, Dhaka. \\ ${ }^{3}$ Department of Pathology, National Institute of Ophthalmology, Sher-e-Bangla Nagar, Dhaka
}

\begin{abstract}
Helicobacter pylori eradication is the mainstay in the treatment of Helicobacter pylori associated peptic ulcer disease. Furazolidone was tried in several developing countries and showed good results in some trials. Increasing the duration of treatment has been shown to improve the eradication rate. This study was done to compare the efficacy of triple therapy for two weeks (Group-A) and three weeks (Group-B) consisting of omeprazole $20 \mathrm{mg}$ b.d. amoxicillin $1 \mathrm{gm}$ b.d. and furazolidone $200 \mathrm{mg}$ b.d. in the eradication of Helicobacter pylori in duodenal ulcer patient. A total of 70 duodenal ulcer patients with Helicobacter pylori infection were included in the study. Healing of duodenal ulcer was assessed three months after the end of treatment and at the same time Helicobacter pylori eradication assessed by Campylobacter Like Organism (CLO) test and histology. In group-A, duodenal ulcer was healed in $17(58.62 \%)$ patients and Helicobacter pylori was eradicated in 15(52\%) patients. In group-B, duodenal ulcer was healed in $19(61.30 \%)$ patients and Helicobacter pylori was eradicated in $18(58 \%)$ patients. Healing of duodenal ulcer was not significantly different between two groups. Eradication of Helicobacter pylori was also not significantly different between two groups.
\end{abstract}

\section{Introduction}

Duodenal ulcer disease is one of the most commonly encountered health problem in Bangladesh. The prevalence of duodenal ulcer was estimated to be $11.98 \%^{1}$. Helicobacter pylori is considered as one of the most important etiological factor responsible for duodenal ulcer ${ }^{2}$. Helicobacter pylori is widely prevalent in Bangladesh, with $60 \%$ of children being infected by the age 3 months and $80 \%$ being infected by the age of 3 years $^{3}$. In adults, about $92 \%$ have been found to be seropositive for Helicobacter pylori antibody ${ }^{4}$.

Successful treatment aiming at the cure of Helicobacter pylori infection results in the healing of duodenal ulcer disease and very low recurrence rate ${ }^{5}$. Several international consensus conference $^{6-8}$ recommended that all patients with duodenal or gastric ulcer who have Helicobacter pylori infection should receive anti Helicobacter pylori therapy to cure the infection. In Bangladesh several trials have been conducted in the past with different regimens to treat Helicobacter pylori. Some studies showed high eradication rate ${ }^{9,10}$ and other studies showed low eradication rate ${ }^{11,12}$. In most of the studies in Bangladesh, the eradication was between $30-64 \%{ }^{11,12}$.

Furazolidone, an antimicrobial agent belonging to nitrofuran group proved to be successful against Helicobacter pylori in several trials ${ }^{13,14}$. There is no incidence of resistant strains of Helicobacter pylori against furazolidone yet. This drug is very cheap and there are very few adverse effects. Amoxicillin resistance was found to be low in Bangladesh ${ }^{15}$. Increasing duration of treatment has been shown to improve the eradication rate ${ }^{16}$.

This study was designed to compare the efficacy of triple therapy with furazolidone in combination with amoxicillin and omeprazole for two weeks and three weeks in the eradication of Helicobacter pylori and also to compare the ulcer healing rate.

\section{Materials and Methods}

This study was conducted in the department of Gastroenterology, Bangabandhu Sheikh Mujib Medical University from July 2002 to June 2004. A total of 70 patients with endoscopically proven duodenal ulcer, 15 to 60 years of age, of both sexes were included in this study when Campylobacter Like 
Organism (CLO) test and histology gave positive result. Complicated duodenal ulcer, patients with gastric ulcer, severe concomitant illness, pretreatment with Proton Pump lnhibitors, $\mathrm{H}_{-2}$ receptor antagonist, bismuth preparation or antibiotics within 4 weeks prior to study, patients with regular intake of Non Steroidal Anti Inflammatory Drugs or steroids, pregnant or lactating women were excluded from the study. A complete medical history was obtained and physical examination was performed in each patient. Informed consent was taken from each patient. Socioeconomic status of the patients determined according to the yearly income of the patients. Low economic class-income <Tk 30,000 per annum, middle economic classincome Tk-30,000-Tk-59,900 per annum and high economic class-income $\mathrm{Tk}$ 60,000 and above.

Pretreatment endoscopy of upper Gastro Intestinal Tract was done with Olympus forward viewing video endoscope GIF-0145 to identity the presence, number, size and location of duodenal ulcer and two biopsies were taken from the antrum and one biopsy from the body of the stomach. One biopsy from antrum was used for Campylobacter Like Organism (CLO) test. One biopsy from the antrum and one from the body of the stomach used for histology. Those patients with duodenal ulcer who were found to be positive for Helicobacter pylori by Campylobacter Like Organism (CLO) test and histology were treated with omeprazole (20 mg b.d), amoxicilline (1gm b.d.) and furazolidone (200 mg b.d.) for 2 weeks and 3 weeks.

Drug compliance was monitored by daily drug intake diary maintained by the patient in which the patient was required to mark each dose taken in the day and by counting of empty drug packages (each dose was supplied in one package). The patients were requested to note any adverse effect and to report.

Follow up endoscopy of upper Gastro Intestinal Tract was performed in all patients, three months after the end of therapy. Presence or absence of ulcer healing was checked. Biopsies from the antrum and body of the stomach were repeated. Biopsy samples were studied by Campylobacter Like Organism (CLO) test (one biopsy from antrum) and histology (one biopsy from antrum and one biopsy from body of stomach). Eradication was confirmed by negative result of the Campylobacter Like Organism (CLO) test and histology.

\section{Results}

A total of 70 patients (35 patients in group-A for two weeks therapy and 35 patients in group-B for three weeks therapy) fulfilling the inclusion criteria were enrolled in this study. Base line characteristics of the patients are shown in the table-I. Among those patients, 6 patients from group-A and 4 patients from group-B didn't attend follow-up endoscopy at the end of 3 months (Table-II). The remaining 60 patients $(85.71 \%)$ completed the trial. In group-A, 29 $(82.85 \%)$ patients were follow-up, in group -B, 31 $(88.57 \%)$ patients were followed-up. Total $36(60 \%)$ patients out of 60 patients had their ulcer healed. In group-A, ulcer healed in $17(58.62 \%)$ patients. In group-B, ulcer healed in $19(61.30 \%$ ) patients (TableIII). Comparison between two groups showed no significant difference of ulcer healing $(\mathrm{P}=0.833)$. Helicobacter pylori was eradicated in $33(55 \%)$ patients out of 60 patients. In group-A, Helicobacter pylori eradication was found in $15(52 \%)$ patients. In group-B, Helicobacter pylori eradication was found in $18(58 \%)$ patients. Table-IV. Comparison between two groups showed no significant difference of Helicobacter pylori eradication $(\mathrm{P}=0.622)$.

Patients who completed the trial were fully compliant. Some patients complained of nausea, loss of taste, headache and mild abdominal discomfort. All of these side effects were mild and did not require interruption of treatment. The reasons of dropout of patients in both groups from the study were not clear to us. Possibilities were they were noncompliant to the study. They thought that their symptoms were improved so repeat endoscopy would not help them. They were contacted but did not respond.

Table I: Baseline characteristics of the patients.

\begin{tabular}{lcc}
\hline \multicolumn{1}{c}{ Parameters } & $\begin{array}{c}\text { Group A } \\
\mathrm{n}=35\end{array}$ & $\begin{array}{c}\text { Group B } \\
\mathrm{n}=35\end{array}$ \\
\hline Age & $\begin{array}{c}33.71 \pm 10.90 \\
\text { Mean } \pm \mathrm{SD}\end{array}$ & $\begin{array}{c}34.63 \pm 13.36 \\
16-55\end{array}$ \\
$\begin{array}{l}\text { Range } \\
\text { Sex }\end{array}$ & 32 & 30 \\
$\quad$ Male & 3 & 5 \\
$\quad$ Female & & \\
Socioeconomic status & 23 & 24 \\
$\quad$ Low & 12 & 11 \\
$\quad$ Middle & 11 & 13 \\
Smoking & & 22 \\
Yes & 24 &
\end{tabular}

Group-A : Omeprazole, Amoxicillin and Furazolidone- 2 weeks.

Group-B : Omeprazole, Amoxicillin and Furazolidone- 3 weeks.

Table II: Patients attending at 3 months follow up.

\begin{tabular}{|c|c|c|c|c|}
\hline \multirow[t]{2}{*}{ Groups } & \multicolumn{2}{|c|}{$\begin{array}{l}\text { Patients } \\
\text { attended }\end{array}$} & \multirow{2}{*}{\multicolumn{2}{|c|}{$\begin{array}{l}\text { Patients dropped out } \\
\text { No }(\%)\end{array}$}} \\
\hline & No & $(\%)$ & & \\
\hline$A(n=35)$ & 29 & $(82.86)$ & 6 & (17.14) \\
\hline $\mathrm{B}(\mathrm{n}=35)$ & 31 & (88.57) & 4 & (11.43) \\
\hline Total & 60 & $(85.71)$ & 10 & (14.29) \\
\hline
\end{tabular}


Table III: Duodenal ulcer healing in two groups:

\begin{tabular}{lcccc}
\hline \multicolumn{1}{c}{ Groups } & \multicolumn{2}{c}{ Patients in } & \multicolumn{2}{c}{ Patients in whom } \\
& $\begin{array}{c}\text { whom duodenal } \\
\text { ulcer healed }\end{array}$ & \multicolumn{2}{c}{$\begin{array}{c}\text { duodenal ulcer did } \\
\text { not heal }\end{array}$} \\
& \multicolumn{2}{c}{ No } & $(\%)$ & \multicolumn{2}{c}{ No } & $(\%)$ \\
\hline A $(\mathrm{n}=29)$ & 17 & $(58.62)$ & 12 & $(41.38)$ \\
B $(\mathrm{n}=31)$ & 19 & $(61.30)$ & 12 & $(38.70)$ \\
\hline Total $(\mathrm{n}=60)$ & 36 & $(60)$ & 24 & $(40)$ \\
\hline
\end{tabular}

Table IV: Helicobacter pylori eradication in two groups:

\begin{tabular}{lcccc}
\hline \multirow{1}{*}{ Groups } & \multicolumn{2}{c}{$\begin{array}{c}\text { Patients in whom } \\
\text { Helicobacter } \\
\text { pylori eradicated } \\
\text { No }\end{array}$} & \multicolumn{2}{c}{$\begin{array}{c}\text { Patients in whom } \\
\text { Helicobacter pylori } \\
\text { not eradicated } \\
\text { No }\end{array}$} \\
\hline A $(\mathrm{n}=29)$ & 15 & $(52)$ & 14 & $(48)$ \\
B $(\mathrm{n}=31)$ & 18 & $(58)$ & 13 & $(42)$ \\
\hline Total $(\mathrm{n}=60)$ & 33 & $(55)$ & 27 & $(45)$ \\
\hline
\end{tabular}

\section{Discussion}

Antimicrobial treatment of Helicobacter pylori is difficult because of the habitat occupied by the organism below the layer of mucous adherent to gastric mucosa. It is also difficult because of resistance of the organism to antimicrobial agent specially to nitroimidazole ${ }^{17,18}$ and macrolides ${ }^{19}$. These factors have led to the concurrent use of several drugs as exemplified by triple and quadruple regimens. Even the most effective regimen available today fails in $5-20 \%$ cases $^{20}$. This picture is more disappointing in Bangladesh with low eradication rates ${ }^{11,12}$ and higher rates of re-infection ${ }^{21,22}$. In most of the studies in Bangladesh, the eradication rate was between $30-64 \%^{11,12}$. However, most studies in other developing countries showed also much lower eradication rates and higher rates of recurrence than those obtained in developed countries ${ }^{23-25}$. Increasing the duration of treatment has been shown to improve the eradication rate ${ }^{16}$. In India, study compairing two weeks therapy with three weeks therapy has found a better eradication rate in the three weeks group ${ }^{26}$.

In this prospective study we have compared the efficacy and safety of 2 weeks and 3 weeks of furazolidone based triple therapy. Furazolidone, an antimicrobial agent belonging to nitrofuran group proved to be successful against Helicobacter pylori in several trials ${ }^{12,13}$. There is no incidence of resistant strains of Helicobacter pylori-against furazolidone. Amoxicillin resistance was found to be low in Bangladesh ${ }^{15}$. This study has shown eradication rate of $52 \%$ in group-A and $58 \%$ in group-B, which is parallel with the rates of the most other studies in Bangladesh. But the rate is much lower than other countries.
Smoking has a relation with peptic ulcer healing. Ulcer healing is delayed in smokers. In our study ulcer healing was delayed in smokers. Smokers were advised to stop smoking during study but some patients did not stop due to addiction.

Socioeconomic status has a role in the prevalence of Helicobacter pylori infection. There is increased prevalence of Helicobacter pylori infection in low socioeconomic status. But socioeconomic status has no relation with peptic ulcer healing.

In one study ${ }^{13} 30$ patients with histologically documented Helicobacter pylori infection received combination of bismuth subcitrate $240 \mathrm{mg}$ b.d. furazolidone $100 \mathrm{mg}$ q.d.s. and amoxicillin $500 \mathrm{mg}$ q.d.s. for 14 days. H. pylori eradication rate was $86 \%$.

In another study ${ }^{14} 140$ patients were randomly assigned to received a one week course of furazolidone $100 \mathrm{mg}$ b.d. and clarithromycin $250 \mathrm{mg}$ b.d. with either tripotassium dicitrato-bismuthate 240 $\mathrm{mg}$ b.d. (FCB group) or lansoprazole $30 \mathrm{mg}$ daily (FCL group) and clarithromycin $250 \mathrm{mg}$ b.d. and omeprazole $20 \mathrm{mg}$ daily with either furazolidone 100 $\mathrm{mg}$ b.d. (FCO group) or metronidazole $400 \mathrm{mg}$ b.d. (MCO group). Four weeks after the end of therapy eradication rate was in the FCB, FCL, FCO and MCO groups were $91 \%, 91 \%, 86 \% 74 \%$ respectively. High eradication rate may be due to clarithromycin.

The optimal duration of treatment remains controversial. Two reports from the United States showed an improvement when the treatment is given for a longer time: 14 days greater than 10 days greater than 7 days $^{27}$. In France, Lamouliatte et al. ${ }^{28}$ compared regimens of Lansoprazole, amoxicillin and clarithromycin given for 7 days and 10 days and found a significant difference favoring a 10 days duration. In India compared regimens of Lansoprazole, amoxicillin and tinidazole given for 7 days, 14 days and 21 days and found better eradication rate in latter group ${ }^{29}$. In this study compared regimens of omeprazole, amoxicillin and furazolidone given for 14 days and 21 days and fund no significant different of Helicobacter pylori eradication between the 14 days and 21 days treatment duration.

From this study, it appears that adequate eradication rates are not achieved by Helicobacter pylori eradication therapy in duodenal ulcer patients with drug regimens shown to result in high eradication rates in developed countries. Low rates of eradication has been found in both two weeks and three weeks therapy. Eradication rate does not improve if duration of treatment increase from two weeks to there weeks. This low eradication rate may be due to development 
of resistance to newer anti Helicobacter pylori regimen. A study from Mumbai reported resistance to amoxicillin $73 \%$ and furazolidone $91 \%{ }^{29}$. Resistance to amoxicillin in developed countries is either nil or less than $1 \%$ indicating that it is not yet a problem ${ }^{30}$. Bangladesh is a developing country where it is difficult to eradicate Helicobacter pylori and therapy recommended for the developed countries may not be appropriate for the Bangladeshi population and regimens based on culture and sensitivity profile may be helpful. Another factor for low eradication rate may be due to bacterial virulence factors ${ }^{31}$. CagA negative strains have been shown to be a risk factor for treatment failure. Marais et al. ${ }^{31}$ showed that Helicobacter pylori eradication was $87 \%$ of CagA positive strains while only $69 \%$ of CagA negative strains could be eradicated. However, the CagA and VacA status in this study was not known. It is also possible that other virulence factors may be involved in the bacterial response to Helicobacter pylori eradication therapy.

The present study of two weeks and three weeks triple therapy with furazolidone, amoxicillin and omeprazole did not show a markedly high Helicobacter pylori eradication rate at an acceptable level. Ulcer healing rate was also lower than that of other studies conducted in the different countries of the world. So further studies are needed to find out factor or factors responsible for the low eradication rate in Bangladeshi patients and to find out a more effective eradication therapy.

\section{References}

1. Hasan M, Ali SMK, Azad Khan AK. Peptic ulcer in Bangladesh: an endoscopic survey. Gut 1985; 16 : Al 17.

2. Suerbaum S and Michetti P. Helicobacter pylori infection. NEJM 2002; 347: 1175-86.

3. Mahalanabis D, Rahman MM, Sarkar SA, Bardhan PK, Hildebrand P, Beglinger C, et al. Helicobacter pylori infection in the young in Bangladesh, prevalence socioeconomic and nutritional aspects. Int J Epidemiol 1996; 25: 894-898.

4. Ahmad MM, Rahman M, Rumi AK, Islam S, Huq F, Chowdhury MF, et al. Prevalence of Helicobacter pylori in asymptomatic population-a pilot serological study in Bangladesh. J Epidemiol 1997; 7: 251-254

5. Bapat MR, Abraham P, Bhandarker PV, Phadke AY, Joshi AS. Acquisition of Helicobacter pylori infection and reinfection after its eradication are uncommon in Indian adults. Indian J Gastroenterol 2000; 19:172-174.
6. NIH Consensus Conference Development panncl. Helicobacter pylori in peptic ulcer disease. JAMA 1994; 272: 65-9.

7. European Helicobacter pylori study group current European concepts in the management of Helicobacter pylori infection. The Maastricht concensus report. Gut 1997; 41: 8-13.

8. The Report of Digestive Health Initiative International. Update conference on Helicobacter pylori. Gastroenterology 1997; 113: S4-S8.

9. Ahmad MM, Rahman M, Rahman M, Raihan ASMA, Roy PK, Rahman MT, et al. Two weeks combination therapy with antimicrobials and anti- ulcer agents in duodenal ulcer patients -A comparative study of different regimens in the healing of duodenal ulcer and eradication of Helicobacter pylori. Bangladesh J Medicine 1998; 10:4-9.

10. Rahman MT, Miah MAR, Roy PK. Study of efficacy of 10 days triple therapy with omeprazole plus two antimicrobials in the eradication of Helicobacter pylori in patients with peptic ulcer diseases in Bangladesh. Bangladesh J Medicine 2002; 13: 40-44.

11. Rahman MM, Hussain SMB, Ahmed Z, Siddiqui MAM, Hossain R, Uddin MM, et al. A prospective study of three different Helicobacter pylori eradication regimens in the treatment of peptic ulcer disease. Bangladesh Armed Forces Medical Journal 2001/2002; 29: 1-4.

12. Khan MR, Rasul K, Hasan M. H.pylori eradication therapy for duodenal ulcer disease in Bangladeshi patients by two triple drug regimens: results of a clinical trial. Bangladesh J Med 2003; 14: 39-41.

13. Segura AM, Gutierrez O, Otero W, Angel A, Genta RM, Graham DY. Furazolidone, amoxicillin and bismuth triple therapy for Helicobacter pylori infection. Aliment Pharmacol Ther 1997; 11:529-532.

14. Liu WZ, Xiao SD, Shi Y, Wu SM, Zhang DZ, Xu WW, et al. Furazolidone containing short term triple therapy are effective in the treatment of Helicobacter pylori infection. Aliment Pharmacol Ther 1999;13:317-322.

15. Nahar S, Mukhopadhyay AK, Khan R, Ahmad MM, Datta S, Chattopadhyay S, Dhar SC, Sarker SA, Engstrand L, Berg DE, Nair GB, Rahman M. Antimicrobial susceptibility of Helicobacter pylori strains isolated in Bangladesh. J Clin Microbiol 2004; 42: 4856-8.

16. Laine L, Estrada R, Trujillo M. Randomized comparison of differing periods of twice-a-day triple therapy for the eradication of Helicobacter pylori. Aliment Pharmacol Ther 1996; 10: 1029-1033.

17. Banatvala M, Davis GR, Abdi Y, Clements L, Rampton DS, Hardie JM, et al. High prevalence Helicobacter pylori metronidazole resistance in migrants to east London: relation with previous metronidazole exposure and gastroduodenal disease. Gut 1994;35:1562-1566.

18. Pilatto A, Rassu M, Leandro G. Prevalence of Helicobacter pylori resistance to antibiotics in Northeast Italy: A multicenter study. GISU. Interdisciplinary Group for this of ulcer. Dig Liver Dis 2000; 32:763-767. 
19. Glupcxynski Y, Megraud F, Lopez Brea M. European Multicenter study of in vitro antimicrobial resistance in Helicobacter pylori. Eur $\mathrm{J}$ Clin Microbial Infect Dis 2000; 11: 820-823.

20. Bazzoli F. Key points from the revised Maastricht Consensus Report: The impact on general practice. Eur J Gastroenterol Hepatol 2001; 13(suppl 2):3-7.

21. Jain Ak, Dayal VM. Helicobacter pylori recolonization and ulcer relapse after its eradication in India. Indian J Gastroenterol 1997; I6:(suppl 1): S22-4.

22. Hildebrand $\mathrm{P}$, Brandhar $\mathrm{P}$, Rossi L, Parvin S, Rhaman A, Arefm MS, et al. Recrudescence and reinfection with Helicobacter pylori after eradication therapy in Bangladeshi adults. Gastroenterology 2001; 121: 792-798.

23. Ramirez-Ramos A, Gilman RH, Barua LR, Recavarren-Arce S, Watanbe J, Salazar G, Checkley W, Mc Donald J, Valdez Y, Cardera L, Carrazco J. Rapid Recurrence of Helicobacter pylori infection in Peruvian patients after successful eradication. Gastrointestinal Physiology working group of the Universidae Peruana Cayetana Heredia \& The John Hopkins University. Clin Infect Dis 1997; 25: 1027-31.

24. Coelho LGV, Passos MCF, Chausson Y, Costa EL, Maia AF, Barando MJ, Rodrigues DC, Gastro LP. Duodenal ulcer and eradication of Helicobacter pylori in a developing country. An 18 months follow-up study. Scand J Gastroenterol 1992; 27: 362-365.
25. Wheeldon TU, Hoang TT, Phung DC, Björkman A, Granström M, Sörberg M. Long-term follow-up of Helicobacter pylori eradication therapy in Vietnam: reinfection and clinical outcome. Aliment Pharmacol Ther 2005; 21: 1047-1053.

26. Chaudhary A, Ahuja V, Bal CS, Das B, Pandey RM, Sharma MP. Rank order of success favors longer duration of therapy for Helicobacter pylori in duodenal ulcer disease. A randomized pilot study. Helicobacter 2004; 9(2): 124-9.

27. Laine L, Estrada R, Trujillo M. Randomized comparison of differing periods of twice-a-day triple therapy for the eradication of Helicobacter pylori. Aliment Pharmacol Ther 1996; 10:1029-1033.

28. Lamouliatte H, Forestier S, Perie F. Lansoprazole $30 \mathrm{mg}$ or $60 \mathrm{mg}$ combined with two antibiotics (amoxicillin and clarithromycin) to eradicate Helicobacter pylori. Gut 1998; 43 (suppl 2): A 80.

29. Mhaskar M, Sandhu N, Abraham P. In vitro antimicrobial susceptibility of Helicobacter pylori strains in Indian patients (Abstract). Indian J Gastroenterol 1997; 16 (suppl 1): $\mathrm{S} 35$.

30. Magraud F. Helicobacter pylori antibiotic resistance. Prevalence, importance and advance in testing. Gut 2004; 53: $1374-1384$.

31. Marais A, Monteiro L, Lamouliatte H. cagA negative status of Helicobacter pylori is a risk factor for failure of PPI based triple therapies in non-ulcer dyspepsia (Abstract). Gastroenterology 1998; 114: A 214. 